\title{
Cigarette Dosing Unit
}

National Cancer Institute

\section{Source}

National Cancer Institute. Cigarette Dosing Unit. NCI Thesaurus. Code C116245.

A dosing unit equal to the amount of ingredient(s) in a cigarette. 